\title{
Prevalence and Burden of Human Immunodeficiency Virus and Hepatitis B Virus Co-infection in Nigeria: A Systematic Review and Meta-Analysis
}

Lukman Femi Owolabi ${ }^{1 *}$, Aliyu Ibrahim¹, Baba Maiyaki Musa², Baffa Adamu Gwaram ${ }^{3}$, Abdulhamid Isa Dutse $^{3}$, Muhammad Hamza $^{4}$, Ahmad $^{2}$ Maifada Yakasai ${ }^{4}$, Abdulrazaq G Habib ${ }^{4}$ and Musa Muhammad Borodo 5

${ }^{1}$ Neurology Unit, Aminu Kano Teaching Hospital, Bayero University, Kano, Nigeria

${ }^{2}$ Pulmonology Unit, Aminu Kano Teaching Hospital, Bayero University, Kano, Nigeria

${ }^{3}$ Clinical Hematology Unit, Aminu Kano Teaching Hospital, Bayero University, Kano, Nigeria

${ }^{4}$ Infectious Disease Unit, Aminu Kano Teaching Hospital, Bayero University, Kano, Nigeria

${ }^{5}$ Gastroenterology Unit, Aminu Kano Teaching Hospital, Bayero University, Kano, Nigeria

\begin{abstract}
Background: Studies on HIV/HBV co-infection in Nigeria yielded prevalence ranging between $10 \%$ and $70 \%$, giving the widest variation in prevalence of HIV/HBV co-infection from studies emanating from any country all over the world. However, estimation of clinical and public health impacts of HIV/HBV co-infection requires a robust and reliable epidemiological data for an appropriate estimation of the logistical, economic, and humanitarian impact of the two viruses in Nigeria.
\end{abstract}

Objective: The aim of this review was to estimate the prevalence and burden of HBV infections in HIV-infected patients in Nigeria.

Methods: Estimates were derived from a random effects meta-analysis of observational studies reporting the prevalence of HBV/HIV in Nigeria. The derived estimate for the prevalence of HBV/HIV co-infection was applied to the total HIV-infected populations in Nigeria to give an estimated burden of HBV/HIV co-infection in Nigeria.

Result: Thirty three studies with quality data from seventeen states in Nigeria, up to December 16, 2013, were included. I-squared heterogeneity was $98 \%$. Random effect model (REM) estimate of prevalence among HIV-infected patients from the 33 studies was $15 \%(95 \% \mathrm{Cl} 13-17)$. The prevalence of HIV/HB co-infection among attendees of HIV clinics was $17 \%$ [95\% Cl 13-20], among pregnant HIV-infected patients were $10 \%$ [95\% Cl 6-15], $12 \%$ [95\% Cl 6-17] among HIV-infected children and among newly discovered HIV-infected voluntary blood donor (VBD) patients $10 \%$ [95\% Cl 6-15]. Meta- regression showed no significant associations between the mean age of the patients, the proportion of female patients, year of the study and prevalence of co-infection. The burden of HBV/HIV co-infection in Nigeria, based on the estimate, was 984000 C.I. [852 800-1115 200].

Conclusion: In Nigeria, the estimated prevalence of HBV/HIV infection is $15 \%$ resulting in a substantial burden for the country.

Keywords: Prevalence; HIV; HBV; Co-infection; Nigeria

\section{Introduction}

An estimated 33.2 million people are infected with the human immunodeficiency virus (HIV) worldwide [1]. It was estimated that more than $60 \%$ of the infected population are in sub-Saharan Africa [2]. In Nigeria, HIV prevalence among the general population is $4.1 \%$ with about 3.1 million people living with HIV and about 300,000 new infections occurring annually [3].

Similarly, infection with hepatitis B virus (HBV) is a serious public health problem in the country $[4,5]$. Nigeria has remained a hyperendemic area of hepatitis B virus infection, with an estimated $12 \%$ of the total population being chronic carriers in spite of the availability of a safe and effective vaccine [6]. In Nigeria, universal childhood vaccination against the HBV started less than fifteen years ago and its coverage has increased over the years.

$\mathrm{HIV} / \mathrm{HBV}$ co-infection is a growing concern because apart from increasing the toxicity to antiretroviral medications, [7] coinfected patients have higher levels of HBV replication, lower rates of spontaneous resolution of the HBV infection, and higher risk of reactivation of previous infections, and thus, are at an increased risk of developing cirrhosis of the liver [8].

Apart from their ability to integrate within the host genome, a process which is obligatory for the life cycle of HIV but not for HBV
[9], HBV and HIV have similar properties such as transmission using a reverse transcriptase enzyme in replication, tendency to develop chronic infections, and an immense capacity of mutation in their genome, causing rapid emergence of mutant strains, some of which are resistant to widely used anti-viral agents [9]. Consequently, knowledge of country-by-country prevalence of HBV/HIV co-infection may impact positively on prevention and treatment strategy of HBV /HIV co-infection in the country of interest.

The impact of co-infection is particularly important in places with widespread use of antiretroviral therapy. As the use of ART increasingly becomes prevalent in certain regions of the world with high HBV endemicity and as long term survival increases, It is likely

*Corresponding author: Lukman Femi Owolabi, Neurology unit, Department of Medicine, Aminu Kano Teaching Hospital, Bayero University, PMB 3452, Kano, Nigeria, Tel: 2348023244583; E-mail: drlukmanowolabi@yahoo.com

Received March 09, 2014; Accepted May 02, 2014; Published May 15, 2014

Citation: Owolabi LF, Ibrahim A, Musa BM, Gwaram BA, Dutse Al, et al. (2014) Prevalence and Burden of Human Immunodeficiency Virus and Hepatitis B Virus Co-infection in Nigeria: A Systematic Review and Meta-Analysis. J AIDS Clin Res 5: 308. doi:10.4172/2155-6113.1000308

Copyright: (c) 2014 Owolabi LF, et al. This is an open-access article distributed under the terms of the Creative Commons Attribution License, which permits unrestricted use, distribution, and reproduction in any medium, provided the original author and source are credited. 
that liver disorder following chronic HBV in HIV-infected population may emerge as a greater public health problem than before [10]. This potential problem was suggested in a meta-analysis that reported on 12382 patients living in Europe which found a significant $36 \%$ excess risk of all-cause mortality attributed to the effect of HBV co-infection in HIV patients (pooled effect estimate, 1.36; 95\% CI, 1.12-1.64) [11]. Furthermore, establishing a reliable estimate of HIV/HBV burden will facilitate provision of ART regimens that are effective on both HIV and HBV infections such as Tenofovir and either Lamivudine or Emtricitabine ART two drug backbone.

Against this background, a number of studies that were conducted on HIV/HBV co-infection in Nigeria, using HB surface antigen as a marker, yielded prevalence ranging between $10 \%$ and $70 \%$ giving the widest variation in prevalence of HIV/HBV co-infection from studies emanating from any African country or the world at large.

A systematic review pooling studies conducted on HIV/HBV coinfection in Sub-Saharan Africa reported overall prevalence estimate of $15 \%$ [12]. However, while such sub continental values may have their advantages, the country specific prevalence rate may better inform country specific prevention and treatment policies of $\mathrm{HIV} / \mathrm{HBV}$ infections.

With the use of HAART in HIV-infected individuals in Nigeria with high HBV endemicity, it is likely that liver disease from chronic hepatitis B will emerge as an even greater problem in a foreseeable future. Therefore, it is important to estimate the national HIV/HBV coinfection prevalence in Nigeria with the view to further expand and streamline antiretroviral programs, especially in view of the implications of using HAART agents that also possess anti-HBV activity.

Furthermore, estimation of clinical and public health impacts of $\mathrm{HIV} / \mathrm{HBV}$ co-infection requires a robust and reliable epidemiological data for a fair estimations of the logistic, economic, and humanitarian impact of HIV/HBV co-infections in Nigeria. Accordingly, it is presumed that this review will go a long way in guiding future policies on prevention and treatment of HIV/HBV co-infection in the country.

The aim of this review was to estimate the prevalence and burden of HBV co-infections in the general and subgroup populations of HIVinfected patients in Nigeria.

\section{Methods}

\section{Literature search}

An English-language literature search was conducted on PubMed, EMBASE, ISI, African journals online (AJOL) and Endnote databases, existing systematic reviews, specialty journals, several websites and other search engines such as Google. Medical subject heading (MeSH) terms were used in the search for relevant articles before December 16, 2013 using a search criterion combination of the following key words: hepatitis $B$ (with or without hepatitis $\mathrm{C}$ ), HBV as defined by HBS antigen positivity, HBV-DNA, human immunodeficiency virus, HIV, AIDS and co-infection AND Nigeria. To make our searches more effective, combination of these keywords was also explored. Titles and/or abstracts of the search results were screened to determine the relevance of the studies. Full-texts of selected studies were also reviewed. (Search date $16 / 12 / 2013-28 / 12 / 2013)$. When required, we contacted the authors and also manually searched the reference lists of all identified publications and recent systematic reviews. Book chapters, and review articles on the subject were also consulted. Titles and abstracts identified by electronic searches were examined independently by two investigators on-screen, to select potentially relevant studies. All studies that evaluated the point prevalence of hepatitis B in HIV infected patients were considered prima facie relevant.

The estimate derived from the prevalence of HBV/HIV co-infection was applied to the total HIV-infected populations in Nigeria to give an estimated burden of HBV/HIV co-infection in Nigeria.

Conducting and reporting of this study were in accordance with the guidelines on Meta-analysis of Observational Studies in Epidemiology (MOOSE) and Preferred Reporting Items for Systematic Reviews and Meta-analysis (PRISMA) statements [13,14].

\section{Inclusion and exclusion criteria}

Studies that reported HBV prevalence data of HIV-infected patients in Nigeria, using at least HB surface antigen detection method, were selected for inclusion. Publications including fewer than $40 \mathrm{HIV}-$ infected individuals or studies that did not include data on patients who were infected with both HBV and HIV were excluded. Studies in which patient selection was based on the presence of liver disease, studies from outside Nigeria and studies without original or with inadequate data were also excluded.

\section{Data extraction}

Data were extracted, ascertained and recorded in a standardized form that is used to record relevant items and entered into a database. Information recorded included information on authors, year of publication, state of Nigeria, where the study was conducted, study design, study characteristics, setting, serological test for hepatitis B, age of participants, proportion of female gender, sources of bias, quality measures, absolute numbers of HIV-infected patients, absolute numbers of HIV/ HBV- co-infected patients that were either provided or could be calculated from the available data and any relevant observations or comments. Two of the investigators independently checked the extracted data for accuracy.

\section{Quality assessment}

A 12-point scoring system was used to rate the quality of the articles retrieved. Scoring was conducted by two independent investigators using a modification of the Downs and Black checklist [15]. The score was based on 12-point questions (objective of the study clearly described, study design clearly stated, participants representative of the population from which they were recruited, participants accrued during the same time period, modest sample size, management of missing data, age, gender and other characteristics explored/reported, e.g., were confounders reported, was detection method of HBV reported, were potential biases reported, was outcome clearly described?), The assessment also included other items known to be associated with study quality [16]. The studies were classified into three levels that represented their quality. The total score was 12 with a higher score indicating better quality.

\section{Data analysis}

The primary outcome measure was the prevalence of hepatitis $\mathrm{B}$ in HIV-infected patients. The standard error of prevalence was determined by binomial probability distribution. The prevalence $(\mathrm{P})$ of $\mathrm{HBV} / \mathrm{HIV}$ co-infection, which was expressed in percentage with the respective $95 \%$ confidence interval $(95 \% \mathrm{CI})$, was calculated for each study. The $\log \mathrm{P}$ and the standard error of $\log \mathrm{P}$ were computed for the respective studies. Meta-analyses were conducted for prevalence estimates. Given the inherent variability among observational studies, 
we combined results and obtained meta-analysis estimates using a random effects model (REM) by DerSimonian and Laird for estimate summary and 95\% confidence intervals (95\% CIs) from included studies [12]. We evaluated statistical heterogeneity by conducting tests of between-study heterogeneity and I squared $\left(\mathrm{I}^{2}\right)$ statistics with $\mathrm{I}^{2}>50 \%$ denoting substantial heterogeneity, tau squared $\left({ }^{\prime} \mathrm{I}^{2}\right)$ and Gailbrath plot. We performed sensitivity analysis to examine the impact of specific publications on the overall prevalence. Subsequently, restricted scenario or sub-group analyses were performed on data derived from studies with similar characteristics. Publication bias and small study effect were assessed by visual inspection funnel plots and by using Begg's adjusted rank correlation tests and Egger's regression asymmetry test $[17,18]$. Given the inconsistency and the insensitivity of the tests [19], publication bias was considered to exist only if detected in both tests. We also performed univariate, weighted, least-squares metaregressions to identify study-level characteristics (mean or median age of participants, years of study and proportion of female participants) associated with prevalence. All analyses were carried out using Stata version 12.0 (Stata Corp., College Station, TX, USA).

\section{Result}

\section{Overview of selected studies and characteristics of participants in studies}

A total of 153 citations was identified on electronic search and other sources. On the basis of titles, abstracts, relevance and duplication 103 records were excluded. Thus, a total of 50 articles was screened. After a full-text review, a further 17 articles were excluded. The remaining 33 studies that satisfied the inclusion criteria and were of satisfactory quality were included in the analysis (Figure 1 and Table 1). The Characteristics of the studies and quality assessment scores are presented in Table 1. The studies were conducted in the six geopolitical

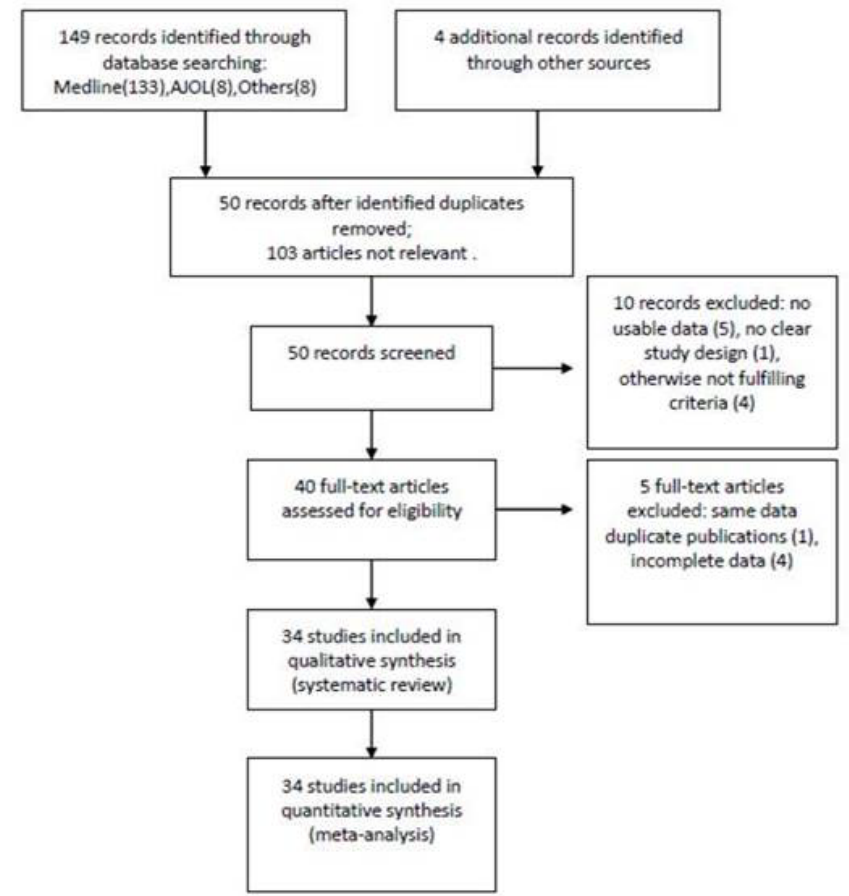

Figure 1: Flow diagram of the process of article selection for the meta-analysis and review.

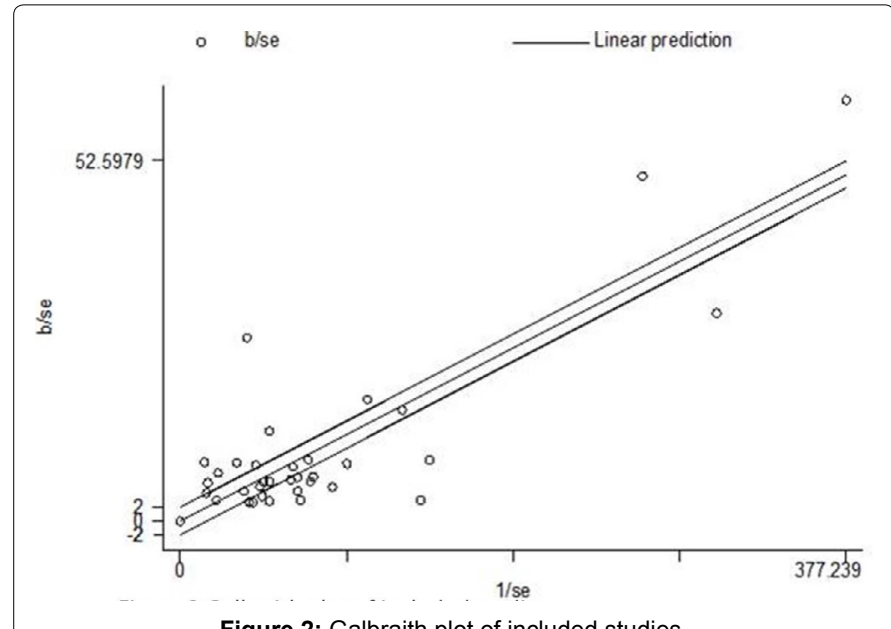

Figure 2: Galbraith plot of included studies

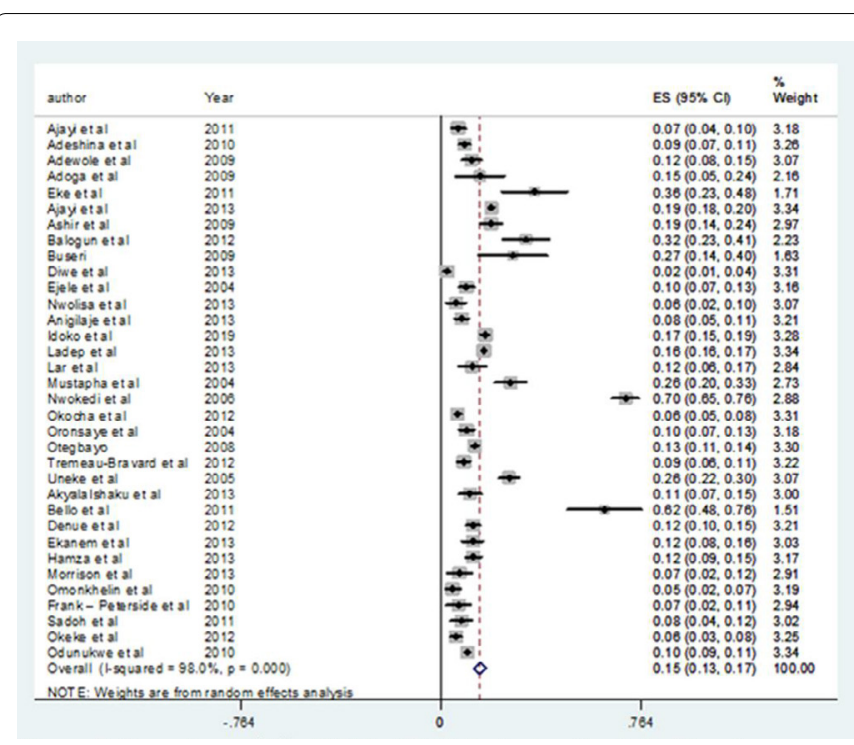

Figure 3: Prevalence (\%) of HB in HIV -infected patients in Nigeria.

zones (17 states) of Nigeria namely southwest-7, southeast-7, southsouth-6, northwest-2, northeast-3, north central-9 (Table 1). The studies with a point prevalence of HIV/HBV co-infection in study subgroup populations that consisted of the HIV clinic (HC) attendants, children (Chi), voluntary blood donors (VBD), pregnant women (Pre) and one cohort of prison (Pri) inmates were included in the subgroup analysis (Table 1). All of the 33 studies were conducted in urban areas [20-52]. Two $[25,29]$ of the studies were prospective, three $[40,41,51]$ were retrospective, one [22] had retrospective and prospective arms and the remaining studies were cross sectional design. The total number of HIV-infected participants was 53899 in the 33 studies analyzed. Overall, the age of the participants ranged between 0.7 and 84 years.

\section{Findings from the meta-analysis}

Galbraith plots (Figure 2) showed that there was between studies variation in the pooled studies. Figure 3 showed forest plots of the pooled studies and the overall prevalence. Heterogeneity chi-squared was 1610.84 (d.f. $=33$ ) p=0.000, I-squared (variation in ES attributable to heterogeneity) was $98.0 \%$ and estimate of between-study variance Tau-squared was 0.0043 . 
Citation: Owolabi LF, Ibrahim A, Musa BM, Gwaram BA, Dutse Al, et al. (2014) Prevalence and Burden of Human Immunodeficiency Virus and Hepatitis B Virus Co-infection in Nigeria: A Systematic Review and Meta-Analysis. J AIDS Clin Res 5: 308. doi:10.4172/2155-6113.1000308

Page 4 of 9

\begin{tabular}{|c|c|c|c|c|c|c|c|c|c|}
\hline Author & $\begin{array}{l}\text { Geopolitical } \\
\text { zone of } \\
\text { Nigeria }\end{array}$ & $\begin{array}{l}\text { State of } \\
\text { Nigeria }\end{array}$ & $\begin{array}{c}\text { Study } \\
\text { population }\end{array}$ & $\begin{array}{l}\text { Study } \\
\text { design }\end{array}$ & $\begin{array}{c}\text { Mean/ } \\
\text { Median age }\end{array}$ & $\begin{array}{c}\text { Age } \\
\text { range }\end{array}$ & $\begin{array}{c}\text { Gender } \\
\text { (female)\% }\end{array}$ & $\begin{array}{c}\text { Number of HB-HIV co- } \\
\text { infection/ Number of HIV } \\
\text { patient }\end{array}$ & $\begin{array}{l}\text { Quality Score } \\
\begin{array}{l}(A=9-12) \\
(B=5-8) \\
(C=1-4)\end{array}\end{array}$ \\
\hline Ajayiet al. [22] & sw & Ekiti & $\mathrm{HC}$ & C & 36.2 & $16-79$ & 71.1 & $18 / 273$ & A \\
\hline Adeshina et al. [23] & SW & Oyo & Pre & C & NA & NA & 100 & $64 / 721$ & A \\
\hline Adewole et al. [24] & NC & Abuja & $\mathrm{HC}$ & $R+P$ & 35.1 & $20-49$ & 75.0 & $30 / 260$ & A \\
\hline Adoga et al. [25] & NC & Nasarawa & Pri & C & 29.2 & $15-56$ & 0.0 & $8 / 54$ & A \\
\hline Eke et al. [26] & SE & Anambra & Pre & C & 24.3 & $14-45$ & 100 & $20 / 56$ & A \\
\hline Ajayi et al. [27] & $\mathrm{NE}$ & Northeast & $\mathrm{HC}$ & $\mathrm{P}$ & 37.9 & $15-84$ & 14.7 & $2044 / 10645$ & A \\
\hline Ashir et al. [28] & $\mathrm{NE}$ & Borno & $\mathrm{Ch}$ & C & NA & NA & NA & $54 / 284$ & C \\
\hline Balogun et al. [29] & SW & Lagos & $\mathrm{HC}$ & C & 38.0 & $20-79$ & 68.6 & $33 / 102$ & B \\
\hline Buseri [30] & SW & Oshun & $\mathrm{Ch}$ & C & 32.6 & $18-64$ & 14.9 & $12 / 44$ & B \\
\hline Diwe et al. [31] & SE & Imo & $\mathrm{HC}$ & $P$ & 38.3 & NA & 69.2 & $9 / 404$ & A \\
\hline Ejele et al. [32] & ss & Rivers & $\mathrm{HC}$ & C & NA & NA & 43.9 & $33 / 342$ & B \\
\hline Nwolisa et al. [33] & SE & Imo & $\mathrm{Ch}$ & c & NA & $1.5-17$ & 56.1 & $8 / 139$ & B \\
\hline Anigilaje et al. [34] & NC & Benue & $\mathrm{Ch}$ & c & 7.53 & $0.7-15$ & 61.3 & $31 / 3954$ & A \\
\hline Idoko et al. [35] & NC & Plateau & $\mathrm{HC}$ & C & 33.0 & NA & 63.0 & $262 / 1564$ & A \\
\hline Ladep et al. [36] & NC & Plateau & $\mathrm{HC}$ & C & 4.4 & $2.6-6$ & 56.6 & $3638 / 19408$ & A \\
\hline Lar et al. [37] & NC & Plateau & Pre & C & NA & $16-40$ & 100 & $16 / 135$ & A \\
\hline Mustapha et al. [38] & $\mathrm{NE}$ & Gombe & VBD & $\mathrm{C}$ & 35.5 & $18-65$ & 51.5 & $53 / 200$ & A \\
\hline Nwokedi et al. [39] & NW & Kano & $\mathrm{HC}$ & C & NA & NA & 49.3 & $211 / 300$ & B \\
\hline Okocha et al. [40] & SE & Anambra & M & C & 35.0 & $3-88$ & 10.5 & $74 / 1176$ & B \\
\hline Oronsaye et al. [41] & ss & Edo & VBD & C & NA & NA & NA & $37 / 383$ & B \\
\hline Otegbayo [42] & sW & Oyo & $\mathrm{HC}$ & $\mathrm{R}$ & 34.6 & $15-70$ & 67.0 & $229 / 1779$ & B \\
\hline Tremeau-Bravard et al. [43] & NC & Abuja & $\mathrm{HC}$ & $\mathrm{R}$ & 39.0 & NA & 55.1 & $38 / 443$ & B \\
\hline Uneke et al. [44] & NC & Plateau & $\mathrm{HC}$ & C & 28.5 & $20-40$ & 22.9 & $127 / 490$ & A \\
\hline Akyalalshaku et al. [45] & NC & Nasarawa & $\mathrm{HC}$ & C & NA & $20-60$ & 73.0 & $22 / 200$ & B \\
\hline Bello et al. [46] & SE & Borno & $\mathrm{HC}$ & C & NA & $20-50$ & 88.9 & $11 / 45$ & C \\
\hline Denue et al. [47] & SE & Borno & $\mathrm{HC}$ & C & 34.2 & $14-81$ & 58.5 & $70 / 569$ & A \\
\hline Ekanem et al. [48] & ss & Uyo & $\mathrm{HC}$ & C & NA & $1.5-65$ & 67.4 & $29 / 239$ & B \\
\hline Hamza et al. [49] & NW & Kano & $\mathrm{HC}$ & C & 34.4 & NA & 59.6 & $54 / 440$ & B \\
\hline Opara-Morrison et al. [50] & sW & Lagos & $\mathrm{HC}$ & C & NA & $18-60$ & 63.0 & $7 / 100$ & B \\
\hline Omonkhelin et al. [51] & SS & Edo & $\mathrm{HC}$ & $\mathrm{R}$ & NA & $17-70$ & 65.0 & $9 / 200$ & B \\
\hline Frank - Petersideet al. [52] & ss & Plateau & Pre & C & NA & NA & 100 & $7 / 105$ & B \\
\hline Sadoh et al. [53] & ss & Edo & $\mathrm{Ch}$ & C & 6.8 & $0.8-17$ & 41.3 & $12 / 135$ & A \\
\hline Okeke et al. [54] & SE & Enugu & Pre & $\mathrm{R}$ & 36.2 & $22-43$ & 100 & $23 / 401$ & A \\
\hline Odunukwe et al. [55] & sW & Lagos & $\mathrm{HC}$ & C & NA & NA & 59.9 & $831 / 8309$ & B \\
\hline
\end{tabular}

SW(South West) SS(south South), SE(South East), NC(North Central) NW(North West), NE(North East), HC(HIV clinic), Ch(Children) Pre(Pregnant women), VBD( Voluntary blood donor), Pri (Prison), NA(Data not available), C(Cross sectional study), R(retrospective study).

Table 1: Characteristics of included studies on HBV/HIV coinfection in Nigeria. 


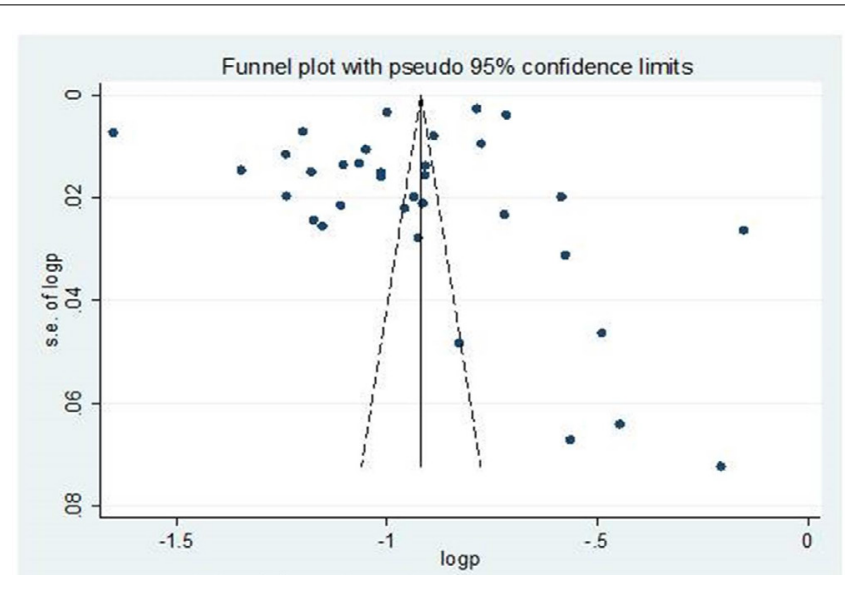

Figure 4: Funnel plot of the studies included.

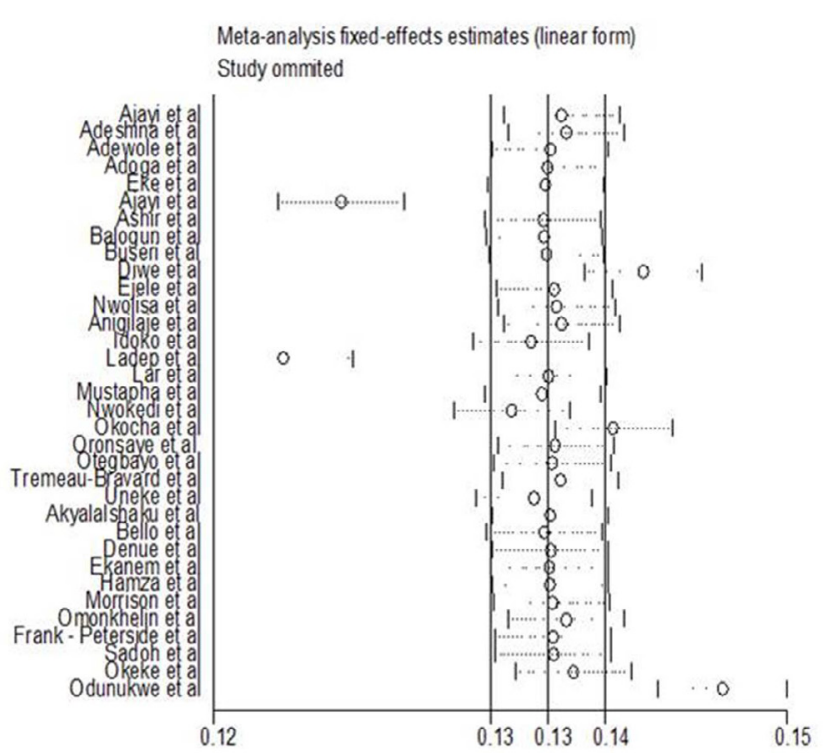

Figure 5: Sensitivity analysis of the studies included
The REM estimate of prevalence among HIV-infected patients from 33 studies was $15 \%$ (95\% CI 13-17\%) (Figure 3). There was a publication bias in Egger's, and Begg's testing (Begg's test, $\mathrm{p}=0.003$; Egger's test, $\mathrm{p}=0.000$ ). This finding was also evident in the funnel plot shown in Figure 4. On sensitivity analysis, i.e. the weight of individual studies on the pooled summary effect showed that the prevalence estimate was dominated by Ajayi et al. [25], Ladep et al. [54] and Odunukwe [52] studies (Figure 5).

Meta-regression was conducted only on studies reporting Mean/ Median age (19 studies) and the proportion of female gender (31 studies) and year of study. In the analysis, study-specific prevalence estimates showed no significant associations with mean age of the participants and the proportion of female participants: mean/median age of patients in years ranging from 4.4 to 39.0 years had a slope coefficient of 0.00024 ( $95 \%$ CI- 0.0037597 to $0.0042334, p=0.902$ ) in 20 studies; proportion of female patients, ranging from $0 \%$ to $100 \%$, had a slope coefficient of 0.00027 ( $95 \%$ CI -0.0024 to $0.0019, \mathrm{p}=0.801$ ) in 31 studies, and year of the study, ranging from 2000 to $2013 \mathrm{had}$ a slope coefficient of -0.01175 ( $95 \%$ CI-0.02738 to $0.00389, \mathrm{p}=0.135$ ) in 31 studies (Figure 6).

\section{Subgroup analysis}

In view of the significant heterogeneity recorded in the overall metaanalysis which could be partly explained by different study populations in the composite studies, we performed a subgroup analysis by study population.

The subgroup analysis showed that the prevalence of HIV/HBV co-infection among attendees of HIV clinics was 17\% [95\% CI 13-20] with heterogeneity statistic of 1331.8 and degree of freedom (df) of 19 $(\mathrm{P}<0.0001), \mathrm{I}^{2}=98.6$ and $\mathrm{I}^{2}$ statistic was 0.004 . The prevalence of HIV/ HBV co-infection among pregnant HIV-infected patients was $10 \%$ [95\% CI 6-15] with heterogeneity statistic of 25.4 and df of $4(\mathrm{P}<0.0001)$, $\mathrm{I}^{2}=84$ and $\mathrm{I}^{2}$ statistic was 0.002 . The prevalence of $\mathrm{HIV} / \mathrm{HBV}$ coinfection among HIV-infected children (Ch) was 12\% [95\% CI 6-17] with heterogeneity statistic of 29.5 and $\mathrm{df}$ of $4(\mathrm{P}<0.0001), \mathrm{I}^{2}=86$ and $\mathrm{I}^{2}$ statistic was 0.003 . The prevalence of HIV/HBV co-infection among HIV-infected voluntary blood donor (VBD) patients was 10\% [95\% CI 6-15] with heterogeneity statistic of 25.4 and df of $4(\mathrm{P}<0.0001), \mathrm{I}^{2}=84$ and' $\mathrm{I}^{2}$ statistic was 0.002 (Figure 6).

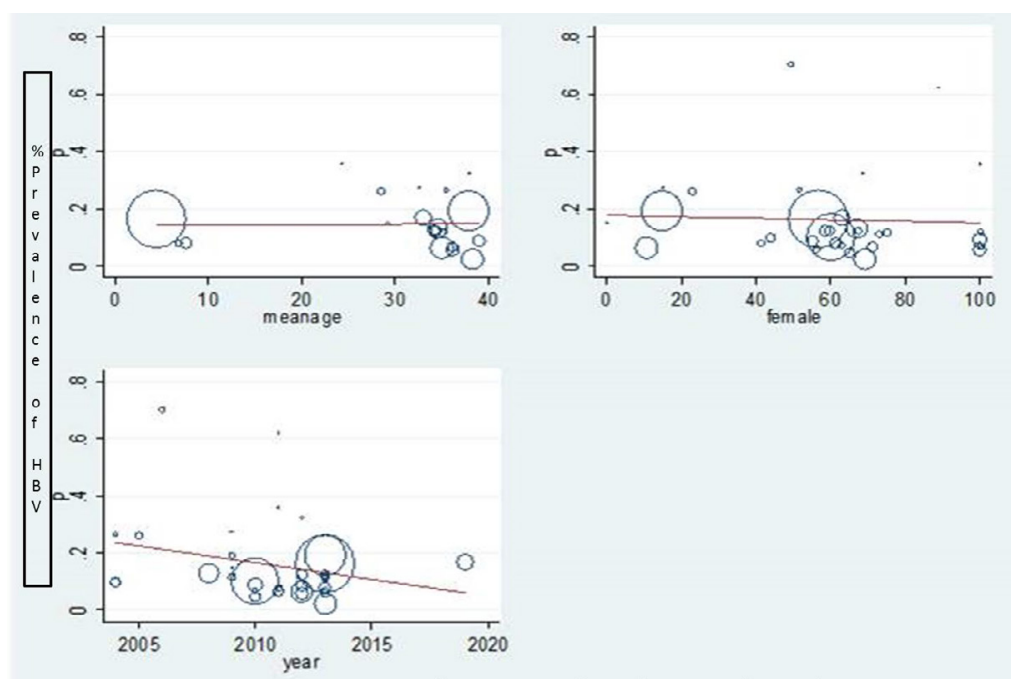

Figure 6: Meta-regression of HB in HIV infected patients by study parameters. 


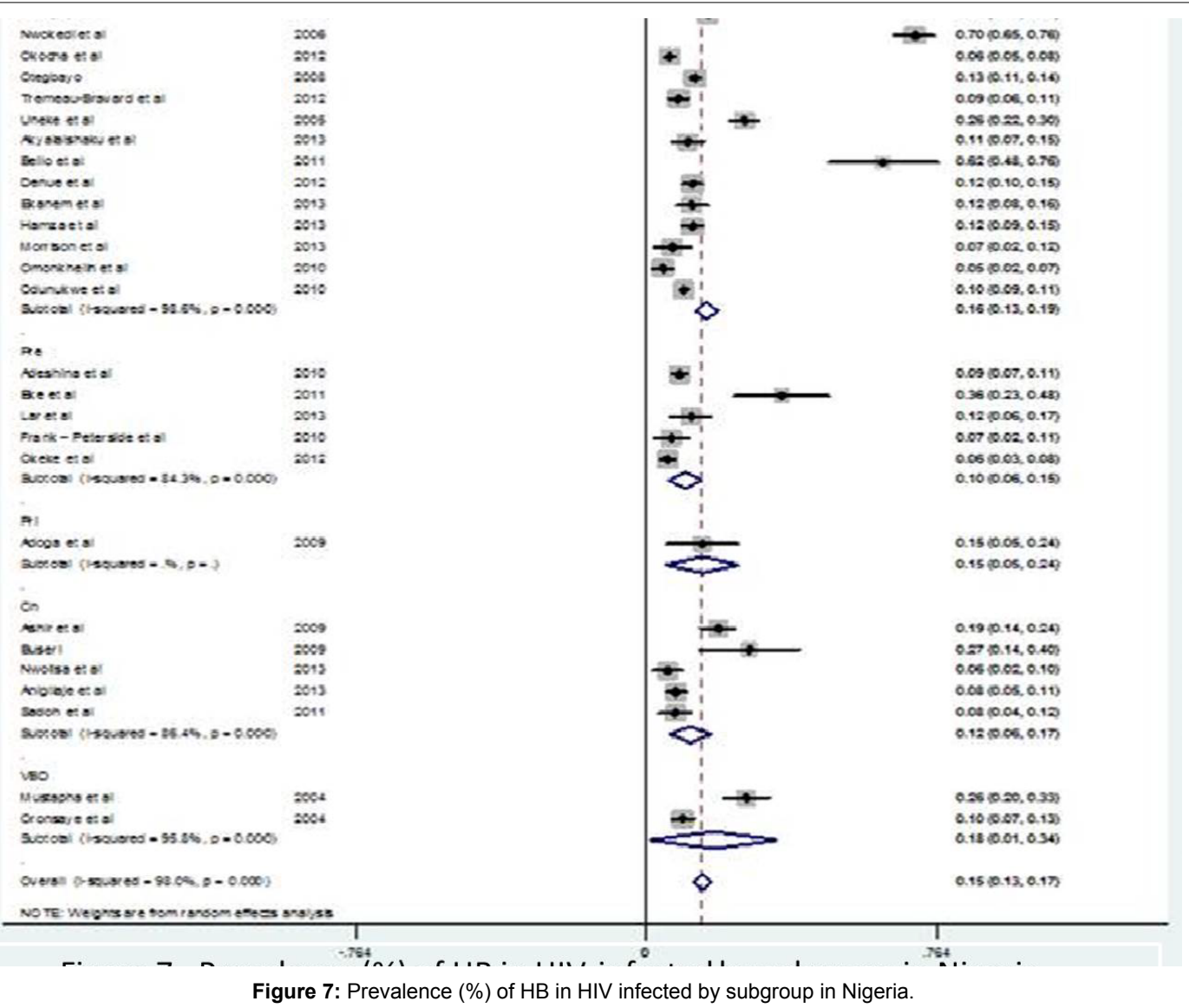

Figure 7 showed the forest plot result when the pooled studies were stratified on the basis of geopolitical region in Nigeria.

The overall pooled prevalence of HBV/HIV co-infection was $15 \%$ (95\% CI 13-17\%). Assuming Nigeria has an estimated population of 160 , million people [20] and HIV seroprevalence rate of $4.1 \%$ [21], the overall burden based on our estimates would be 984000 C.I. [852 800 $1115200]$.

\section{Discussion}

To the best of our knowledge, this is the first meta-analysis of hepatitis B HIV co-infection prevalence studies in Nigeria.

In this study, our meta-analysis examined the prevalence of coinfection with HBV/HIV-infected patients in Nigeria by analyzing 33 studies [22-54] that were widely distributed across the six geopolitical zones of the country. The overall analysis showed that a considerable number of HIV-infected patients are co-infected with hepatitis $B$ virus. The overall prevalence of HIV/HBV co-infection was $15 \%$. Barth et al., in a similar study using studies from Sub Saharan Africa, reported prevalence of $15 \%$ for the subcontinent [12]. Therefore, our finding further corroborated the sub-Saharan study, the similarity between the findings in the two studies could be attributed to the fact that the aggregate number of participants from studies from Nigeria constituted more than $40 \%$ of the overall population of the participants in that particular study. Separate reports from the Malawi, Cote D'Ivoire and Tanzania on hepatitis B prevalence in HIV-infected individuals ranged between 9.0-16.9\% [55-57]. In view of the fact that nearly all the studies we have analyzed were cross-sectional studies, the overall estimate found is indicative of the point prevalence of $\mathrm{HBV} /$ HIV co-infection.

In areas, such as Australia, Europe and North America, where HBV endemicity is low, HBV and HIV infection are commonly acquired in adulthood through sexual or percutaneous transmission. In such areas, the prevalence of chronic co infection is about 5-7\% among HIVinfected patients [58]. Conversely, in countries with intermediate and high HBV endemicity, such as in sub-Saharan Africa, the main routes of transmission of $\mathrm{HBV}$ are either perinatal or in early childhood, and in these regions HBV co-infection rates are 10-20\% [59-61]. This HBV/ HIV co-infection prevalence is exemplified by our finding.

Our finding is also a reflection of reports from the other, though individual, studies from different regions of Nigeria, who had observed high prevalence of $\mathrm{HBV}$ infection in the general population ranging between $10.3 \%$ and $15.1 \%[44,62]$.

The HIV epidemic in Nigeria is complex and its prevalence varies widely by region. In some states of the country, the epidemic is more concentrated in certain group and is driven by high-risk behaviors, while other states tend to have more generalized epidemics that are sustained primarily by multiple sexual partnerships in the general population. Since HBV and HIV have similar mode of transmission one would expect a similar trend for HBV infection. In light of this, we conducted a region based analysis of our data, the NW region of the country appeared to have the highest (41\%) prevalence of HBV/ HIV co-infection. This finding is, however, constrained by the fact that only two studies were conducted in the region and both of them were from the same center and on similar participants, yet yielding a wide 
difference in HBV/HIV co-infection prevalence (12\% [47] and $70.3 \%$ [37]). Otherwise, the other regions had prevalences close to the overall prevalence HBV/HIV co-infection we found in Nigeria.

Unlike in the east and southeast Asia, where perinatal transmission predominates, [63] in Africa most infections are believed to occur in children, with vertical transmission having a less important role [64] and most HBV infections occur in the first 5 years of life [65].

In this study, a lower prevalence of HBV/HIV co-infection was obtained among children (12\%) compared to their adult counterpart (16\%). In conformity with this finding, two cross-sectional surveys from Ethiopia [66] and Somalia [67] reported a lower prevalence of HBV markers in children than in adults, suggesting either an increase adult infection or a decline in childhood infections over time [68]. This finding is partly a reflection of the high endemicity of HBV in the general population which is sustained possibly by vertical transmission in Nigeria. Nonetheless, the finding of such a high prevalence of HBV/ HIV co-infection of $12 \%$ in the HIV-infected child population studied partly suggest either poor adherence to vaccination schedules or relatively low vaccination coverage in the country.

Hepatitis B in HIV-infected women in pregnancy is of great concern. $\mathrm{HBV} / \mathrm{HIV}$ co-infected pregnant women in resource poor setting, like Nigeria, face huge challenges of mother to child transmission. The overall prevalence obtained in our analysis, which is higher than the figures found in the USA and western Europe [69] is largely a reflection of endemicity of HBV infection in Nigeria. The high prevalence of $\mathrm{HBV} / \mathrm{HIV}$ co-infection in voluntary blood donors in Nigeria further underscores the need for screening for the two viruses in every blood donor.

In the current study, meta-regression of mean age, proportion of the female gender and year of study, which was conducted to explore associations with prevalence failed to confirm significant relationships. Nevertheless, there was a non-significant decreasing trend in prevalence of HBV/HIV co-infection with increasing year of study. This finding may be partly attributed to the impact of hepatitis B immunization in Nigeria.

The figures obtained in this meta-analysis could be considered modest estimates of the various prevalences because the pooled studies did not account for cases of occult HBV infections which are described as the existence of HBV DNA without detectable HBsAg. Antibodies against hepatitis $B$ core antigen (anti-HBc) are often the only serum markers in such patients. Thus, in cases with high risk of hepatitis $B$ where HBsAg is negative, it is necessary to check anti-HBc level to detect HBV infection. None of the studies in this analysis conducted identification of $\mathrm{HBV}$ in HIV-infected individuals using this means thereby raising the possibility of underestimation of the prevalence of $\mathrm{HBV}$ in HIV-infected patients.

The magnitude of heterogeneity in the current study deserves further mention. There are several possible sources of variability or heterogeneity among the pooled studies including Clinical heterogeneity arising from differences in participant characteristics (e.g., sex, age, baseline disease severity, ethnicity, comorbidities) which can cause statistical heterogeneity and methodological heterogeneity which hinges on aspects of the conduct of the individual study and how they differ from each other.

This study does not, in any way, underestimates the fact that only a large representative national epidemiological study conducted at the same time can give a more reliable overall prevalence of $\mathrm{HBV} / \mathrm{HIV}$ co- infection in Nigeria. However, in the absence of such a national survey, a meta-analysis of all the observational studies cutting across all the geopolitical zones of Nigeria, provides the best evidence and hence, could be of use in improving the care of HIV/AIDS and HIV/HBV coinfected patients.

\section{Conclusion}

In Nigeria, the overall prevalence of HBV/HIV infection is high $(15 \%)$ resulting in a substantial burden. This finding, which is similar to what obtains in other Sub Sahara Africa countries, has a great implication for management HIV-infected and HIV/HBV co-infected patients in the country. Observation systems seem necessary to monitor infection patterns to target high prevalence regions and high risk groups. Our finding could be a veritable guide for future policies on HBV and HIV treatment and prevention strategies in Nigeria.

\section{References}

1. Joint United Nations Program on HIVIAIDS (2007) AIDS epidemic update December 2007. World Health Organization, Geneva.

2. United Nations Program on HIV/AIDS (UNAIDS), World Health Organization (WHO) (2007) AIDS epidemic update: December 2007.

3. UNAIDS Report on the global AIDS Epidemic 2010.

4. Department of Health (UK) (2013) Hepatitis B: The Green Book.In Immunization against Infectious Disease, 161-184.

5. André $F$ (2004) Hepatitis B: a comprehensive prevention, diagnosis, and treatment program--past, present, and future. J Gastroenterol Hepatol 19 Suppl: S1-4.

6. Ugwuja El (2010) Seroprevalence of Hepatitis B surface Antigen and liver function tests among adolescents in Abakaliki, South Eastern. Internet Journal of Tropical Medicine 6: 1-6

7. Feld JJ, Ocama P, Ronald A (2005) The liver in HIV in Africa. Antivir Ther 10: 953-965.

8. Gilson RJ, Hawkins AE, Beecham MR, Ross E, Waite J, et al. (1997) Interactions between HIV and hepatitis B virus in homosexual men: effects on the natural history of infection. AIDS 11: 597-606.

9. Mphahlele MJ, Lukhwareni A, Burnett RJ, Moropeng LM, Ngobeni JM (2006) High risk of occult hepatitis B virus infection in HIV-positive patients from South Africa. J Clin Virol 35: 14-20.

10. Hoffmann CJ, Thio CL (2007) Clinical implications of HIV and hepatitis B coinfection in Asia and Africa. Lancet Infect Dis 7: 402-409.

11. Nikolopoulos GK, Paraskevis D, Hatzitheodorou E, Moschidis Z, Sypsa V, et al. (2009) Impact of hepatitis B virus infection on the progression of AIDS and mortality in HIV-infected individuals: a cohort study and meta-analysis. Clin Infect Dis 48: 1763-1771.

12. Barth RE, Huijgen Q, Taljaard J, Hoepelman Al (2010) Hepatitis B/C and HIV in sub-Saharan Africa: an association between highly prevalent infectious diseases. A systematic review and meta-analysis. Int J Infect Dis 14: e1024-e1031.

13. Stroup DF, Berlin JA, Morton SC, Olkin I, Williamson GD, et al. (2000) Metaanalysis of observational studies in epidemiology: a proposal for reporting. Meta-analysis Of Observational Studies in Epidemiology (MOOSE) group. JAMA 283: 2008-2012.

14. Moher D, Liberati A, Tetzlaff J, Altman DG, PRISMA Group (2009) Preferred reporting items for systematic reviews and meta-analyses: the PRISMA statement. Ann Intern Med151: 264-269

15. Downs SH, Black N (1998) The feasibility of creating a checklist for the assessment of the methodological quality both of randomised and nonrandomised studies of health care interventions. J Epidemiol Community Health 52: 377-384.

16. Habib AG, Yakasai AM, Owolabi LF, Ibrahim A, Habib ZG, et al. (2013) Neurocognitive impairment in HIV-1-infected adults in Sub-Saharan Africa: a systematic review and meta-analysis. Int J Infect Dis 17: 820-831. 
17. Begg CB, Mazumdar M (1994) Operating characteristics of a rank correlation test for publication bias. Biometrics 50: 1088-1101.

18. Egger M, Davey Smith G, Schneider M, Minder C (1997) Bias in meta-analysis detected by a simple, graphical test. BMJ 315: 629-634.

19. Higgins JP, Thompson SG, Deeks JJ, Altman DG (2003) Measuring inconsistency in meta-analyses. BMJ 327: 557-560.

20. National Population Commission (2006) List of Nigerian States by Population. Federal republic of Nigeria Census.

21. National HIV Seroprevalence Sentinel Survey (2008) Process and Findings. National AIDS/STDs Control Program (NASCP) Federal Ministry of Health, Abuja.

22. Ajayi GO, Omilabu SA, Alamu D, Balogun Y, Badaru S (2011) Seroprevalence of other antibodies (herpes, CMV, rubella, varicella, hepatitis $B$ and $C$, syphilis, chlamydia, mumps, toxoplasmosis) in HIV-positive patients. Clin Exp Obste Gynecol 38: 172-174.

23. Adeshina O, Oladokun A, Akinyemi O, Adedokun B, Awolude O, et al. (2010) Human immunodeficiency virus and hepatitis $B$ virus co-infection in pregnancy at the University College Hospital, Ibadan. Afr J Med Med Sci 39: 305-310.

24. Adewole OO, Anteyi E, Ajuwon Z, Wada I, Elegba F, et al. (2009) Hepatitis B and $C$ virus co-infection in Nigerian patients with HIV infection. J Infect Dev Ctries 3: 369-375.

25. Adoga MP, Gyar SD, Pechulano S, Bashayi OD, Emiasegen SE, et al. (2010) Hepatitis B virus infections in apparently healthy urban Nigerians: data from pre-vaccination tests. J Infect Dev Ctries 4: 397-400.

26. Eke AC, Eke UA, Okafor Cl, Ezebialu IU, Ogbuagu C (2011) Prevalence, correlates and pattern of hepatitis B surface antigen in a low resource setting. Virol J 8: 12.

27. Ajayi BB, Moses AE, Denue BA, Bassi PU, Dayar AD, et al. (2013) A 5 -Year review of Hepatitis $B \& C$ viral infection in person living with HIV in northeast Nigeria. Journal of medical research and practice 2:9

28. Ashir GM, Rabasa Al, Gofama MM, Bukbuk D, Abubakar H, et al. (2009) Study of hepatic functions and prevalence of hepatitis B surface antigenaemia in Nigerian children with human immunodeficiency virus infection. Niger $\mathrm{J}$ Med 18: $260-262$

29. Balogun TM, Durojaiye IO, Sagoe A, Emmanuel S (2010) Seroepidemiology of hepatitis-B surface antigenaemia in HIV positive patients. West Afr J Med 29: 169-173.

30. Buseri FI, Muhibi MA, Jeremiah ZA (2009) Sero-epidemiology of transfusiontransmissible infectious diseases among blood donors in Osogbo, south-west Nigeria. Blood Transfus 4:293-299.

31. Diwe CK, Okwara EC2, Enwere OO3, Azike JE4, Nwaimo NC2 (2013) Seroprevalence of hepatitis $B$ virus and hepatitis $C$ virus among HIV patients in a suburban University Teaching Hospital in South-East Nigeria. Pan Afr Med J 16: 7 .

32. Ejele OA, Nwauche CA, Erhabor O (2004) The prevalence of hepatitis $B$ surface antigenaemia in HIV positive patients in the Niger Delta Nigeria. Niger J Med 13: 175-179.

33. Nwolisa E, Mbanefo F, Ezeogu J, Amadi P (2013) Prevalence of hepatitis B coinfection amongst HIV infected children attending a care and treatment centre in Owerri, South-eastern Nigeria. Pan Afr Med J 14: 89

34. Anigilaje EA, Olutola A (2013) Prevalence and Clinical and Immunoviralogica Profile of Human Immunodeficiency Virus-Hepatitis B Coinfection among Children in an Antiretroviral Therapy Programme in Benue State, Nigeria. ISRN Pediatr 2013: 932697.

35. Idoko J, Meloni S, Muazu M, Nimzing L, Badung B, et al. (2009) Impact of hepatitis $B$ virus infection on human immunodeficiency virus response to antiretroviral therapy in Nigeria. Clin Infect Dis 49: 1268-1273.

36. Ladep NG, Agaba PA, Agbaji O, Muazu A, Ugoagwu P, et al. (2013) Rates and impact of hepatitis on human immunodeficiency virus infection in a large African cohort. World J Gastroenterol 19: 1602-1610.

37. Lar PM, Pam VK, Christopher PB, Gwamzhi L, Mawak JD (2013) Prevalence and immune status of HIV/HBV Co-infected pregnant women. Afr J Cln Exper Microbiol 14: 120-126.

38. Mustapha SK, Jibrin YB (2004) The Prevalence of Hepatitis B surface antigenaemia in patients with Human Immunodeficiency Virus (HIV) infection in Gombe, Nigeria. Annals of African Medicine 3: 10-12.

39. Nwokedi EE, Emokpae MA, Dutse Al (2006) Human immunodeficiency virus and hepatitis $\mathrm{B}$ virus co-infection among patients in Kano Nigeria. Niger J Med 15: 227-229.

40. Okocha EC, Oguejiofor OC, Odenigbo CU, Okonkwo UC, Asomugha L (2012) Prevalence of hepatitis B surface antigen seropositivity among HIV-infected and non-infected individuals in Nnewi, Nigeria. Niger Med J 53: 249-253.

41. Oronsaye FE, Oronsaye $\mathrm{JI}$ (2004) Prevalence of HIV-positives and hepatitis B surface antigen-positives among donors in the University of Benin Teaching Hospital, Nigeria. Trop Doct 34: 159-160.

42. Otegbayo JA, Taiwo BO, Akingbola TS, Odaibo GN, Adedapo KS, et al. (2008) Prevalence of hepatitis B and C seropositivity in a Nigerian cohort of HIVinfected patients. Ann Hepatol 7: 152-156.

43. Tremeau-Bravard A, Ogbukagu IC, Ticao CJ, Abubakar JJ (2012) Seroprevalence of hepatitis $B$ and $C$ infection among the HIV-positive population in Abuja, Nigeria. Afr Health Sci 12: 312-317.

44. Uneke CJ, Ogbu O, Inyama PU, Anyanwu GI, Njoku MO, et al. (2005) Prevalence of hepatitis-B surface antigen among blood donors and human immunodeficiency virus-infected patients in Jos, Nigeria. Mem Inst Oswaldo Cruz 100: 13-16.

45. Akyalalshaku A, Ishaleku1 D, Nabe BR (2013) Seroprevalence of Hepatitis B And C Viral Co-infection among Cohort Seropositive HIV patients accessing health care in Nasarawa State North Central, Nigeria. International Journal of Advanced Research 1: 13-19.

46. Bello RH, Olabode HOK (2011) Human immunodeficiency virus (HIV) and hepatitis $B$ virus (HBV) co-infection amongst patients in Biu, Borno stateNigeria. Int Res J Microbiol 2: 507-509.

47. Denue BA, Ajayi B, Abja AU, Bukar AA, Akawu C, et al. (2012) A survey of hepatitis $B$ and $C$ virus prevalence in human immunodeficiency virus positive patients in a tertiary health institution in North Eastern Nigeria Int $\mathrm{J}$ Med Med Sci 4: 13-18.

48. Ekanem US, Eyoh JE, Esubok NU (2013) Prevalence of hepatitis- B virus infection among HIV patients seen in university of UYO teaching hospital (UUTH), UYO. Int J Res Biosciences 2: 92-98.

49. Hamza M, Samaila AA, Yakasai AM, Babashani M, Borodo MM, et al. (2013) Prevalence of hepatitis $B$ and $C$ virus infections among HIV-infected patients in a tertiary hospital in North-Western Nigeria. Niger J Basic Clin Sci 10:76-81.

50. Opara MI, Ogbebor VO, Fasasi MA, Akanmu SA, Bamiro BS, Ayolabi Cl, et al. (2013) Incidences of Hepatitis B and Syphilis Co-Infection with HIV in Antiretroviral Treatment-Naïve Adult Patients Attending APIN Clinic at a University Teaching Hospital in Lagos, Nigeria. J AIDS Clin Res 4:191.

51. Frank-Peterside N, Neenwi D (2009) HIV Infection and HBV Co-infection Survey of Prevalence in Pregnant Women inan Urban Hospital in Port-Harcourt, South - South, Nigeria. Scientia African 9: 133-139

52. Sadoh WE, Fawole AO, Sadoh AE, Oladimeji AO, Sotiloye OS (2006) Practice of universal precautions among healthcare workers. J Natl Med Assoc 98: 722 726.

53. Okeke TC, Obi SN, Okezie OA, Ugwu EO, Akogu SP, et al. (2012) Coinfection with hepatitis $B$ and $C$ viruses among HIV positive pregnant women in Enugu south east, Nigeria. Niger J Med 21: 57-60.

54. Odunukwe N, Okwuzo J, Somefun E, Musa Z, Ezeobi P, et al. (2013) Prevalence and risk factors of HBV/HIV co-infection in Lagos, Nigeria. 6th IAS Conference on HIV Pathogenesis and Treatment: Abstract no. CDB168 ".

55. Franzeck FC, Ngwale R, Msongole B, Hamisi M, Abdul O, et al. (2013) Vira hepatitis and rapid diagnostic test based screening for HBsAg in HIV-infected patients in rural Tanzania. PLoS One 8: e58468.

56. Rouet F, Chaix ML, Inwoley A, Msellati P, Viho I, et al. (2004) HBV and HCV prevalence and viraemia in HIV-positive and HIV-negative pregnant women in Abidjan, Côte d'Ivoire: the ANRS 1236 study. J Med Virol 74: 34-40.

57. Sutcliffe S, Taha TE, Kumwenda NI, Taylor E, Liomba GN (2002) HIV-1 prevalence and herpes simplex virus 2 , hepatitis $C$ virus, and hepatitis $B$ virus infections among male workers at a sugar estate in Malawi. J Acquir Immune Defic Syndr 31: 90-97.

58. Alter MJ (2006) Epidemiology of viral hepatitis and HIV co-infection. J Hepato 44: S6-9. 
Citation: Owolabi LF, Ibrahim A, Musa BM, Gwaram BA, Dutse Al, et al. (2014) Prevalence and Burden of Human Immunodeficiency Virus and Hepatitis B Virus Co-infection in Nigeria: A Systematic Review and Meta-Analysis. J AIDS Clin Res 5: 308. doi:10.4172/2155-6113.1000308

Page 9 of 9

59. Lee HC, Ko NY, Lee NY, Chang CM, Ko WC (2008) Seroprevalence of viral hepatitis and sexually transmitted disease among adults with recently diagnosed HIV infection in Southern Taiwan, 2000-2005: upsurge in hepatitis C virus infections among injection drug users. J Formos Med Assoc 107:404411

60. Nyirenda M, Beadsworth MB, Stephany P, Hart CA, Hart IJ, et al. (2008) Prevalence of infection with hepatitis $B$ and $C$ virus and coinfection with HIV in medical inpatients in Malawi. J Infect 57: 72-77.

61. Diop-Ndiaye H, Touré-Kane C, Etard JF, Lô G, Diaw P, et al. (2008) Hepatitis $B, C$ seroprevalence and delta viruses in HIV-1 Senegalese patients at HAART initiation (retrospective study). J Med Virol 80: 1332-1336.

62. Jombo GT, Egah DZ, Banwat EB (2005) Hepatitis B virus infection in a rura settlement of northern Nigeria. Niger J Med 14: 425-428.

63. Merican I, Guan R, Amarapuka D, Alexander MJ, Chutaputti A, et al. (2000) Chronic hepatitis B virus infection in Asian countries. J Gastroenterol Hepatol 15: $1356-1361$.
64. Vardas E, Mathai M, Blaauw D, McAnerney J, Coppin A, et al. (1999) Preimmunization epidemiology of hepatitis B virus infection in South African children. J Med Virol 58: 111-115.

65. WHO (2012) Protocol 7. Management of hepatitis B and HIV coinfection. HIV AIDS treatment and care. Clinical protocols for the WHO European Region. WHO, Geneva, Switzerland.

66. Abebe A, Nokes DJ, Dejene A, Enquselassie F, Messele T, et al. (2003) Seroepidemiology of hepatitis $B$ virus in Addis Ababa, Ethiopia: transmission patterns and vaccine control. Epidemiol Infect 131: 757-770.

67. Bile K, Abdirahman M, Mohamud O, Aden C, Isse A, et al. (1991) Late seroconversion to hepatitis $B$ in a Somali village indicates the important role of venereal transmission. J Trop Med Hyg 94: 367-373.

68. Hoffmann CJ, Thio CL (2007) Clinical implications of HIV and hepatitis B coinfection in Asia and Africa. Lancet Infect Dis 7: 402-409.

69. Sulkowski MS (2008) Viral hepatitis and HIV coinfection. J Hepatol 48: 353367 